\title{
Examination of the Fundamental Relation between Ionic Transport and Segmental Relaxation in Polymer Electrolytes
}

\author{
Yangyang Wang, ${ }^{a *}$ Fei Fan, ${ }^{a}$ Alexander L. Agapov, ${ }^{a}$ Tomonori Saito, ${ }^{b}$ Jun Yang, ${ }^{c}$ Xiang Yu, ${ }^{b}$ \\ Kunlun Hong, ${ }^{\mathrm{c}}$ Jimmy Mays, ${ }^{\mathrm{a}, \mathrm{b}}$ and Alexei P. Sokolov ${ }^{\mathrm{a}, \mathrm{b}}$
}

\begin{abstract}
Replacing traditional liquid electrolytes by polymers will significantly improve electrical energy storage technologies. Despite significant advantages for applications in electrochemical devices, the use of solid polymer electrolytes is strongly limited by their poor ionic conductivity. The classical theory predicts that the ionic transport is dictated by the segmental motion of the polymer matrix. As a result, the low mobility of polymer segments is often regarded as the limiting factor for development of polymers with sufficiently high ionic conductivity. Here, we show that the ionic conductivity in many polymers can be strongly decoupled from their segmental dynamics, in terms of both temperature dependence and relative transport rate. Based on this principle, we developed several polymers with "superionic" conductivity. The observed fast ion transport suggests a fundamental difference between the ionic transport mechanisms in polymers and small molecules and provides a new paradigm for design of highly conductive polymer electrolytes.
\end{abstract}

Key words: Polymer electrolytes, ionic transport, decoupling, dielectric spectroscopy, Walden plot 


\section{Introduction}

Polymer electrolytes are promising materials for a wide variety of applications in electrochemical devices, including rechargeable batteries, supercapacitors, and fuel cells [1-11]. Developing dry polymers with high ionic conductivity has been one of the "holy grails" of electrolyte science. After decades of research, the poor ionic conductivity of dry polymer electrolytes at ambient temperature remains the major obstacle for their applications. According to the classical theory, the ionic transport in a viscous medium is closely coupled to its structural dynamics [12]. In the case of polymers, it was thought that ion migration is controlled by large amplitude structural rearrangement of polymer segments $[8,13]$. Because most polymers have rather high glass transition temperatures $\left(T_{\mathrm{g}}\right)$, their sluggish segmental dynamics seem to be the limiting factor for ionic transport at low temperatures. For many years, the main direction of research in this area has been focused on design of flexible polymers with low $T_{\mathrm{g}}$, where a faster segmental relaxation would lead to a higher conductivity. However, studies of relatively rigid (fragile) polymers have revealed that their ionic conductivity can be decoupled from segmental relaxation [14-18]. These findings have opened the door to a completely different strategy: by decoupling ionic transport from the structural dynamics of the polymer matrix, it might be possible to make polymers with high solid-state ionic conductivity, similar to the well-known superionic crystals and glasses [19-22]. Despite this encouraging progress, the highest conductivities yet achieved in solvent-free polymer electrolytes at ambient temperature remain rather low, typically two or three orders of magnitude lower than that of liquid electrolytes and conducting ceramics [9]. It still remains a fundamental question whether polymers are intrinsically inferior to other electrolytes in terms of their charge transport capability.

Herein, we present a detailed analysis of the relationship between ionic conductivity and structural relaxation in various polymers, small-molecule electrolytes, aprotic ionic liquids, and ceramics. In contrast to the traditional view, we demonstrate that many polymers fall into the category of "superionic" conductors, due to strong decoupling of ionic motion from structural relaxation. Surprisingly, there is a 
fundamental difference between the ionic transport in polymers and small molecules. Our analysis reveals that at the same structural relaxation rate, the ionic mobility in polymers can be orders of magnitude higher than in small-molecular electrolytes, implying a fundamental difference between the charge transport mechanisms in polymers and small molecules. These findings highlight the importance of decoupling ionic transport from structural relaxation for design of solid polymer electrolytes.

\section{Materials and Methods}

\subsection{Materials}

The 2-ethyl-4-methylimidazole (2E4MIm), ionic liquids 1-butyl-3-methyl-imidazolium hexafluorophosphate ([BMIM][PF 6$])$, 1-butyl-3-methyl-imidazolium trifluoroacetate ([BMIM][TFA]) were purchased from Sigma-Aldrich and used as received.

Five polymers were synthesized using conventional free radical (co)polymerization and anionic polymerization [17, 23, 24]: poly(vinyl ethylene carbonate)-co-poly(vinyl acetate) (PVEC-PVAc, weight-average molecular weight $M_{\mathrm{w}}=32.4 \mathrm{~kg} / \mathrm{mol}$, polydispersity index PDI $\left.=1.95\right)$, poly $($ vinyl ethylene carbonate)-co-poly(methoxyethylacrylate) $\left(\right.$ PVEC-PMEA, $\left.M_{\mathrm{w}}=22.3 \mathrm{~kg} / \mathrm{mol}, \mathrm{PDI}=1.83\right)$, poly(vinyl carbonate)-co-poly[poly(ethylene glycol methyl ether methacrylate)] (PVC-PPEGMEMA, $\left.M_{\mathrm{w}}=31.2 \mathrm{~kg} / \mathrm{mol}, \mathrm{PDI}=1.98\right)$, poly[4-(2-methoxyethoxy)methyl styrene] $\left(\right.$ PMOEOMSt, $M_{\mathrm{w}}=5.8$ $\mathrm{kg} / \mathrm{mol}, \mathrm{PDI}=1.22)$, and poly[poly(ethylene oxide styrene) $]$-co-polystyrene $\left(\mathrm{PPEOSt}-\mathrm{PSt}, M_{\mathrm{w}}=11.4\right.$ $\mathrm{kg} / \mathrm{mol}, \mathrm{PDI}=1.26)$. The first three polymers, PVEC-PVAc, PVEC-PMEA, and PVC-PPEGMEMA, were based on the carbonate structure, whereas the last two polymers, PMOEOMSt and PPEOSt-PSt, were based on the polystyrene backbone.

Polypropylene oxide (PPO) with $M_{\mathrm{w}}$ of $425 \mathrm{~g} / \mathrm{mol}$ was purchased from Sigma-Aldrich. The lithium salts included lithium perchlorate $\left(\mathrm{LiClO}_{4}\right)$ (from Alfa Aesar) and lithium bis(trifluoromethane) sulfonimide (LiTFSI) (from Sigma-Aldrich). The polymer electrolytes were prepared by dissolving polymers and lithium salts in appropriate organic solvents (tetrahydrofuran, methanol, or acetone), and subsequently removing the solvent in a vacuum oven at room temperature. For polymers with relatively 
high glass transition temperatures, the mixtures were further dried at elevated temperatures to completely remove the residual solvents. All the salt-polymer mixtures were optically transparent and no crystallization peak was observed in the DSC measurements. The data of polyethylene oxide (PEO) were taken from ref. [25]. The structural information of all the examined polymers is summarized in Table 1.

Table 1. Structural Information for the Polymer Electrolytes

\begin{tabular}{|c|c|c|c|c|c|c|}
\hline Sample Name & Abbreviation & Structure & $\begin{array}{c}M_{\mathrm{w}} \\
{[\mathrm{kg} / \mathrm{mol}]}\end{array}$ & PDI & $\begin{array}{c}T_{\mathrm{g}} \\
{[\mathrm{K}]}\end{array}$ & Composition \\
\hline $\begin{array}{l}\text { Poly(vinyl ethylene } \\
\text { carbonate)-co- } \\
\text { Poly(vinyl acetate) }\end{array}$ & PVEC-PVAc & & 32.4 & 1.95 & 279 & $\begin{array}{l}\text { VEC (39 } \\
\text { mol\%) }\end{array}$ \\
\hline $\begin{array}{l}\text { Poly(vinyl ethylene } \\
\text { carbonate)-co- } \\
\text { Poly(methoxyethylacry } \\
\text { late) }\end{array}$ & PVEC-PMEA & & 22.3 & 1.83 & 264 & $\begin{array}{l}\text { VEC (63 } \\
\text { mol\%) }\end{array}$ \\
\hline $\begin{array}{l}\text { Poly(vinyl carbonate)- } \\
\text { co-Poly[poly(ethylene } \\
\text { glycol methyl ether } \\
\text { methacrylate)] }\end{array}$ & $\begin{array}{l}\text { PVC- } \\
\text { PPEGMEMA }\end{array}$ & & 31.2 & 1.98 & 253 & $\mathrm{VC}(53 \mathrm{~mol} \%)$ \\
\hline $\begin{array}{l}\text { Poly(polyethylene } \\
\text { oxide styrene)-co- } \\
\text { Polystyrene }\end{array}$ & PPEOSt-PSt & 8.8 & 11.4 & 1.26 & 330 & $\begin{array}{c}\text { PEOSt (21 } \\
\text { mol\%) }\end{array}$ \\
\hline $\begin{array}{l}\text { Poly[4-(2- } \\
\text { methoxyethoxy)methyl } \\
\text { styrene] }\end{array}$ & PMOEOMSt & ${ }_{2} \mathrm{O}$ & 5.8 & 1.22 & 257 & homopolymer \\
\hline Polyethylene oxide & PEO & & 2.0 & - & - & homopolymer \\
\hline Polypropylene oxide & PPO & $\mathrm{OH}$ & 0.425 & - & 195 & homopolymer \\
\hline
\end{tabular}




\subsection{Methods}

Broadband dielectric spectroscopy measurements of our polymer electrolytes were carried out on a Novocontrol alpha analyzer with ZGS interface in the frequency range of $10^{-2}-10^{7} \mathrm{~Hz}$. The temperature was controlled by a Novocontrol cryosystem, in which nitrogen was used as the heating/cooling gas. The polymer electrolyte sample under test was sandwiched between gold-plated electrodes (10 and $20 \mathrm{~mm}$ ) with a Teflon spacer of $0.054 \mathrm{~mm}$. The applied voltage was $0.1 \mathrm{~V}$ to avoid any non-linear effects. The samples were annealed at the highest experimental temperature for approximately 30 minutes prior to the dielectric measurement. All the samples were thermally stable over the temperature range of our experiments.

\section{Results}

Representative spectra of the examined polymer electrolytes are shown in Fig. 1. The spectrum typically consists of three major components: (1) polymer segmental (structural) relaxation in the highfrequency region, (2) dc conductivity in the mid-frequency region, and (3) pronounced increase of $\varepsilon^{\prime}$ in the low-frequency region due to the electrode polarization (EP) effect [26-37]. Therefore, information about ionic conductivity and segmental (structural) relaxation in these polymer electrolytes can be obtained simultaneously from the dielectric spectroscopy measurements. The ionic conductivity $(\sigma)$ can be evaluated from the imaginary part of dielectric permittivity $\left(\varepsilon^{\prime \prime}\right)$ in the intermediate-frequency region, where $\varepsilon^{\prime \prime} \approx \sigma /\left(2 \pi f \varepsilon_{0}\right)$, with $f$ being frequency and $\varepsilon_{0}$ being the permittivity in vacuum. The (apparent) molar conductivity $(\Lambda)$ can be further calculated from the total number density $\left(n_{\text {tot }}\right)$ of ions dissolved in polymers (assuming complete dissociation): $\Lambda=\sigma / n_{\text {tot }}$. The calculation of true molecular conductivity $\Lambda_{\text {True }}$ will be discussed in section 4.3 . Because the segmental loss peak is typically covered by conductivity, the structural relaxation time $\left(\tau_{\mathrm{S}}\right)$ is estimated from the maximum in the derivative of the real part of permittivity $\left(\varepsilon^{\prime}\right): \varepsilon_{\mathrm{der}}^{\prime \prime}=(-\pi / 2) \partial \varepsilon^{\prime} / \partial \ln f[38]$ as $\tau_{\mathrm{s}}=1 /\left(2 \pi f_{\max }\right)$. In the case where the determination of $\tau_{\mathrm{S}}$ is influenced by the presence of electrode polarization or trapped 
micro-bubbles [39], the following equation is used to fit the real and imaginary parts of permittivity to disentangle the segmental relaxation from other processes:

$$
\varepsilon^{*}(\omega)=\varepsilon^{\prime}-i \varepsilon^{\prime \prime}=\varepsilon_{\infty}+\sum_{j} \frac{\Delta \varepsilon_{j}}{\left[1+\left(i \omega \tau_{\mathrm{HN}, j}\right)^{\alpha_{j}}\right]^{\beta_{j}}}+\frac{\sigma}{i \varepsilon_{0} \omega}+A \omega^{-n}
$$

where $\varepsilon_{\infty}$ is the value of $\varepsilon^{\prime}(\omega)$ at infinite frequency, $\Delta \varepsilon_{j}$ is the dielectric relaxation strength, $\tau_{\mathrm{HN}, j}$ is the Havriliak-Negami relaxation time, $\alpha_{j}, \beta_{j}$ are the shape parameters of process $j, n$ is related to the slope of EP's high frequency tail, $A$ gives the amplitude of EP, and $\sigma$ is the dc conductivity. The $\tau_{\mathrm{S}}$ is calculated from $\tau_{\mathrm{HN}}$ and shape parameters as [40]:

$$
\tau_{\mathrm{S}}=\tau_{\mathrm{HN}}\left(\sin \frac{\alpha \beta \pi}{2+2 \beta}\right)^{1 / \alpha}\left(\sin \frac{\alpha \pi}{2+2 \beta}\right)^{-1 / \alpha}
$$

The ionic conductivity and polymer segmental relaxation time of these samples follow VogelFulcher-Tammann [41-43] (VFT) type temperature dependence. An example is given in Fig. 2. The inset of Fig. 2 shows the result of differential scanning calorimetry (DSC) measurement of the same sample. According to the convention, at the glass transition temperature $\left(T_{\mathrm{g}}\right)$, the structural relaxation time $\tau_{\mathrm{S}}=100 \mathrm{~s}$. Fig. $2 \mathrm{a}$ demonstrates that the $T_{\mathrm{g}}$ from DSC measurement agrees well with the extrapolated VFT fit of the dielectric relaxation time. This agreement supports the assignment of the primary dielectric relaxation as the polymer segmental (structural) relaxation. The two quantities, molar conductivity $(\Lambda)$ and segmental relaxation time $\left(\tau_{\mathrm{S}}\right)$, determined by the dielectric spectroscopy, will serve as the basis for our analysis of ionic transport in polymer electrolytes. Lastly, it is worth noting that some polymer electrolytes can exhibit micro-phase separation [44]. However, this phenomenon was not observed in the samples other than $\mathrm{PPO} / \mathrm{LiClO}_{4}$. 



Figure 1. Representative spectra of PVC-PPEOMEMA/LiTFSI (3wt\%). (a) Frequency dependence of the real part of dielectric permittivity $\left(\varepsilon^{\prime}\right)$. The electrical response due to electrode polarization and segmental relaxation are highlighted by black and gray rectangles, respectively. (b) Frequency dependence of the imaginary part of dielectric permittivity $\left(\varepsilon^{\prime \prime}\right)$. The purple dashed line indicates the contribution due to dc conductivity. (c) The corresponding derivative spectra. (d) and (e): the conductivity spectra. To demonstrate the fitting of dielectric data, the data at $-20^{\circ} \mathrm{C}$ and $0^{\circ} \mathrm{C}$ are shown as circles, and the corresponding fitting curves are represented by dashed lines. For this particular sample, the fitting function is $\varepsilon^{*}=\varepsilon^{\prime}-i \varepsilon^{\prime \prime}=\varepsilon_{\infty}+\Delta \varepsilon /\left[1+\left(i \omega \tau_{\mathrm{HN}}\right)^{\alpha}\right]+\sigma /\left(i \varepsilon_{0} \omega\right)+A \omega^{-n}$. 

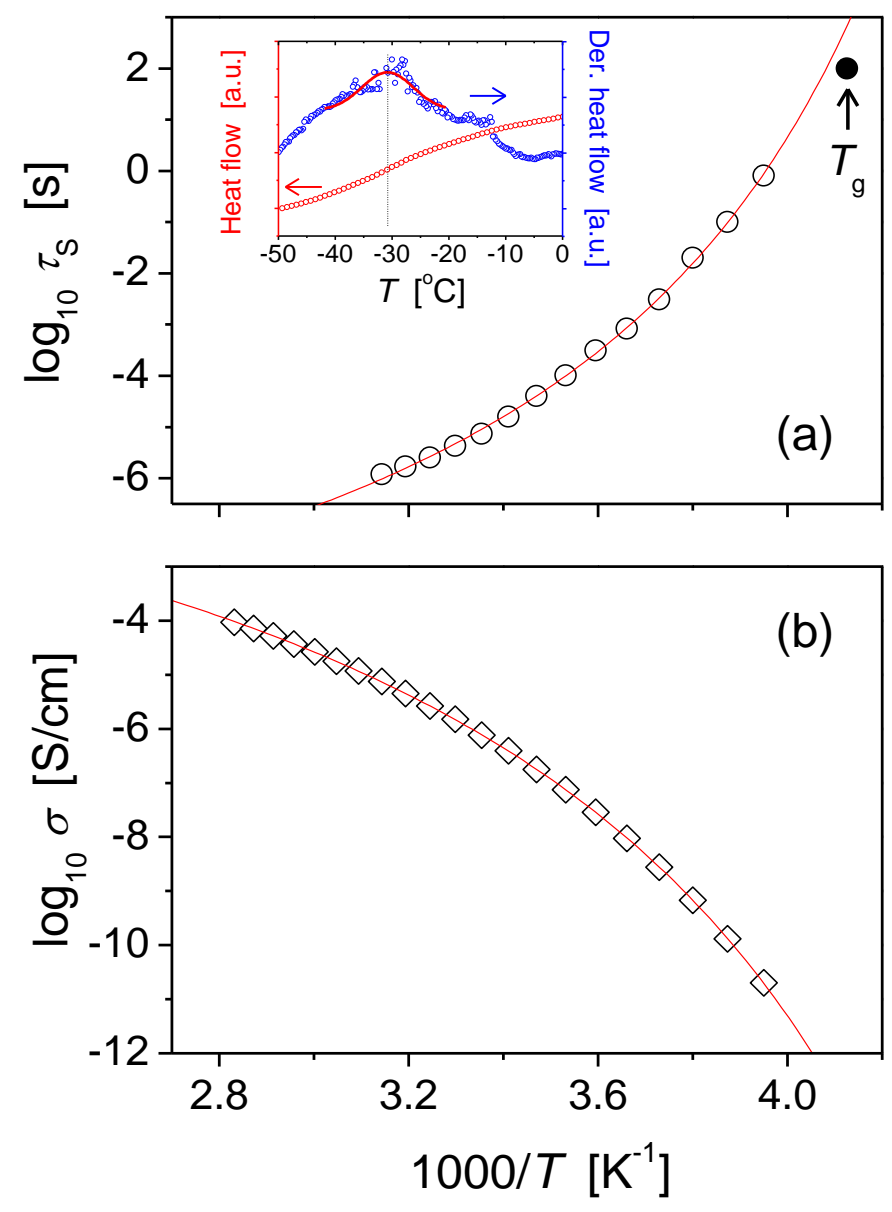

Figure 2. Temperature dependence of (a) the segmental relaxation time $\left(\tau_{\mathrm{S}}\right)$ and (b) ionic conductivity $(\sigma)$ in PVC-PPEOMEMA/LiTFSI (3 wt\%). The solid (red) curves are the fits of experimental data using the VFT equation: $\tau=\tau_{0} \exp \left[B /\left(T-T_{0}\right)\right]$ and $\sigma=\sigma_{0} \exp \left[-B_{\sigma} d\left(T-T_{\sigma}\right)\right]$, where $\tau_{0}, B, T_{0}, \sigma_{0}, B_{\sigma}$, and $T_{\sigma}$ are fit parameters. The inset shows the result of differential scanning calorimetry measurement on cooling $\left(10^{\circ} \mathrm{C} / \mathrm{min}\right)$. The $T_{\mathrm{g}}$ is determined as the temperature of the maximum of the heat flow derivative. The filled (black) circle in Fig. 2(a) represents the $T_{\mathrm{g}}$ value obtained from the DSC, assuming it corresponds to $\tau_{\mathrm{S}} \sim 100 \mathrm{~s}$.

\section{Discussion}

The ionic conductivity in a material is determined by the concentration of free ions $(n)$, their electrical mobility $\left(\mu_{q}\right)$, and the amount of charges carried by the ions $(q)[40,45]$ :

$$
\sigma=n \mu_{q} q
$$


Strictly speaking, one should take the sum over all the ionic species (i), i.e., Eq. 3 should be written in the form of $\sigma=\sum n_{i} \mu_{q, i} q_{i}$. However, in our case, $q_{+}=q_{\text {- }}$ for the $\mathrm{LiClO}_{4}$ and LiTFSI salts. In addition, we will only consider the average mobility of cations and anions for simplicity. Therefore, in this study, Eq. 3 will be used for the discussion of the general principles governing ionic transport.

As a starting-point for our discussion, it is convenient to consider the ionic transport in smallmolecule electrolytes (e.g. salts in water or organic solvents). According to the Einstein relation, the electrical mobility of an ion can be related to its diffusivity $(D)$ :

$$
\mu_{q}=\frac{D q}{k_{\mathrm{B}} T}
$$

where $k_{\mathrm{B}}$ is the Boltzmann constant and $T$ is the absolute temperature. By further assuming the validity of the Stokes-Einstein relation, i.e., $D=k_{\mathrm{B}} T /(C \eta r)$, with $C$ being a constant determined by the ionsolvent interactions, $\eta$ being the viscosity of the medium, and $r$ being the radius of the ion, one can establish the relation between electrical mobility and viscosity:

$$
\mu_{q} \propto \eta^{-1}
$$

Note that according to the Maxwell relation, $\eta=G_{g} \tau_{\mathrm{S}}$ for small-molecule solvents, where $G_{\mathrm{g}}$ is the glassy modulus and $\tau_{\mathrm{S}}$ is the structural relaxation. Therefore, the electrical mobility should be inversely proportional to the structural relaxation time:

$$
\mu_{q} \propto \tau_{\mathrm{S}}^{-1}
$$

The physical picture behind Eq. 6 is that the rate of the charge transport is controlled by the rate of structural rearrangement of solvent molecules $\tau_{\mathrm{S}}^{-1}$. It is well known that the Stokes-Einstein relation alone is insufficient to explain the electrical mobilities of many small ions in aqueous solutions, and the effect of dielectric friction $[12,46-56]$ on $\mu_{\mathrm{q}}$ has to be properly taken into account. Nevertheless, Eq. 6 should still be valid in this case, because the additional dielectric friction exerted by solvent molecules is expected to be proportional to their structural relaxation time $[12,46]$. 
In the case of polymer electrolytes, the size of ion is much smaller than that of solvent molecule (polymer). Therefore, the charge transport should be controlled by the local "microscopic" viscosity $\eta_{\text {micro }}$ rather than the macroscopic viscosity which is defined by the global motion of the entire polymer chain. By assuming that $\eta_{\text {micro }}$ is determined by the polymer segmental (structural) motion, i.e., $\eta_{\text {micro }}=G_{g} \tau_{\mathrm{S}}$, we arrive at the same equation, $\mu_{q} \propto \tau_{\mathrm{S}}^{-1}$, for ion transport in polymer electrolytes. In other words, the rate of ion transport in polymers should be defined by the rate of segmental rearrangements. This is the basis of the classical idea that the ionic conductivity in polymers is defined by segmental (structural) relaxation $[8,13]$.

The derivation of Eq. 6 for polymer electrolytes is based on several assumptions which may not necessarily hold. For example, the Stokes-Einstein relation may breakdown for guest molecule diffusion in polymers, especially in the vicinity of glass transition. Moreover, even if the electrical mobility can be related to microscopic viscosity, it is not obvious whether $\eta_{\text {micro }}$ will be defined by segmental relaxation. Experimentally, it has been shown that the ionic conductivity in polymers can be decoupled from their structural relaxation $[14,17]$. Clearly, our understanding of the relation between ionic transport and polymer segmental relaxation is far from complete and an in-depth analysis seems necessary.

We will start our analysis by examining the relation between the (apparent) molar conductivity $(\Lambda)$ and structural relaxation time (viscosity for small molecules), using the concept of Walden plot. Here, it is helpful to point out a simple fact: the true molar conductivity of free ion $\left(\Lambda_{\text {True }}=\sigma / n\right)$ is directly related to the electrical mobility by the definition of conductivity (Eq. 3):

$$
\Lambda_{\text {True }} / q=\mu_{q}
$$

In other words, $\Lambda_{\text {True }}$ and $\mu_{\mathrm{q}}$ only differ by a constant, which is the amount of charges carried by an ion $(q)$. With this equivalence in mind, we can translate the essence of our analysis into perhaps a simpler language: our goal is to understand the fundamental relation between the ion mobility $\left(\mu_{\mathrm{q}}\right)$ and the rate at which the polymer matrix rearranges its local structure $\left(1 / \tau_{\mathrm{S}}\right)$. 
At this point, it is necessary to clarify the relation of Eq. 6 to several other equations that are frequently used in the analysis of ionic conductors. One of them is the so-called BNN (empirical) relation [57-59], first proposed by Barton, Nakajima, and Namikawa in the 1960s and 1970s, which relates the dc conductivity to the dielectric strength of the low-frequency polarization $(\Delta \varepsilon)$ and the frequency $\left(\omega_{\max }\right)$ corresponding to the maximum of dielectric loss: $\sigma=p \varepsilon_{0} \Delta \varepsilon \omega_{\max }$, where $p$ is a temperature-independent constant of order unity. Another one is the Maxwell relation in dielectrics [6064]: $\sigma=\varepsilon_{0} \varepsilon_{\mathrm{S}} \omega_{\sigma}$, where $\varepsilon_{\mathrm{S}}$ is the static permittivity and $\omega_{\sigma}$ is the macroscopic conductivity relaxation frequency (rate). A microscopic equation for conductivity can be derived by combining the Einstein and Einstein-Smoluchowski equation [65]: $\sigma=\frac{n q^{2}}{k_{\mathrm{B}} T} \frac{\lambda^{2}}{2} \omega_{\mathrm{h}}$, where $\lambda$ is the characteristic diffusion length and $\omega_{\mathrm{h}}$ is the characteristic diffusion or "hopping" frequency. By further assuming that the hopping distance is on the order of Debye length [66], i.e., $\lambda \approx L_{\mathrm{D}}=\sqrt{\varepsilon_{0} \varepsilon_{\mathrm{S}} k_{\mathrm{B}} T /\left(n q^{2}\right)}$, the conductivity can be written as: $\sigma \approx \frac{1}{2} \varepsilon_{0} \varepsilon_{\mathrm{S}} \omega_{\mathrm{h}}$. The above mentioned relations for ionic conductivity and characteristic frequency deal with the intrinsic properties of ion transport itself: the BNN relation connects ion conductivity with dielectric loss caused by ion migration (hopping frequency or electrical relaxation frequency); the Maxwell relation defines the phenomenological conductivity relaxation frequency; and the "hopping" equation provides a microscopic description of the charge transport by linking conductivity with hopping frequency. On the other hand, Eq. 6 addresses the relation between ionic mobility and relaxation of solvent molecules, i.e., how the guest ion diffusion is connected to the molecular motion of the host polymer matrix. In this context, it is worth noting that for polymerized ionic liquids, the ionic transport can be strongly decoupled from polymer structural relaxation, while the BNN relation is nevertheless fulfilled [67]. In this respect the BNN relationship misses the main point of our analysis decoupling of ion motions and structural relaxation of the host, and will not be used in further discussions. 


\subsection{The concept of Walden plot analysis}

The data analysis protocol in this study is inspired by the classical Walden rule [68, 69], which states that the (apparent) molar conductivity $(\Lambda)$ of an electrolyte is inversely proportional to its macroscopic viscosity $(\eta): \Lambda \eta=$ constant. It is easy to see that this relation is a natural consequence of Eq. 3 and 5. The Walden rule provides the basis for a very useful classification of ionic conductors, the so-called Walden plot (Fig. 3). When $\Lambda$ is presented as a function of the fluidity $(1 / \eta)$ of an electrolyte on a double-logarithmic plot, the Walden rule corresponds to a straight line with a slope of one. Dilute aqueous solutions of salts, such as $\mathrm{KCl}$ and $\mathrm{LiCl}$, are often chosen as a reference to represent the ideal case where the ionic interaction is much weaker than thermal energy. In this work, dilute $\mathrm{LiClO}_{4}$ aqueous solution is used as the reference. Since the limiting molar conductivity in water does not vary significantly from one ion to another, the choice of reference is not critical for our analysis. For example, the limiting molar conductivities of $\mathrm{LiClO}_{4}$ and $\mathrm{KCl}$ are 106.0 and $149.85 \mathrm{Scm}^{2} \mathrm{~mol}^{-1}$, respectively [70]. On the scale of a Walden plot, which typically covers more than 10 orders of magnitude on both horizontal and vertical axes, such a small difference is not important.

Electrolytes are usually classified as superionic, if their $\Lambda$ stays above the ideal line, and as subionic conductors if $\Lambda$ is below the ideal line $[69,71,72]$. For example, the inorganic glass $(\mathrm{AgI})_{0.5}\left(\mathrm{AgPO}_{3}\right)_{0.5}$ appears in the top-left corner of the Walden plot (Fig. 3), exhibiting superionic behavior [73, 74]. In contrast, 2-ethyl-4-methylimidazole (2E4MIm), the protic ionic liquids $\alpha$-picolinium acetate $(\alpha \mathrm{Pic}-\mathrm{Ac})$ and methoxypropylammonium nitrate (MOPAN) fall into the subionic regime, due to their low ionicity (low free-ion concentration [72]. Ionic melt $\left[\mathrm{Ca}\left(\mathrm{NO}_{3}\right)_{2}\right]_{0.4}\left[\mathrm{KNO}_{3}\right]_{0.6}(\mathrm{CKN})$ stays on the ideal line at high temperatures (high fluidities), but moves into the superionic regime in the vicinity of the glass transition, due to the well-known decoupling between ionic conductivity and structural relaxation in CKN. "Good"

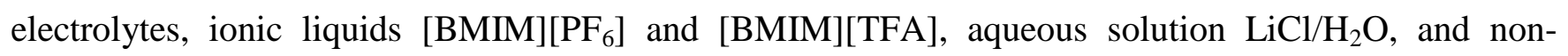
aqueous solutions $\mathrm{LiCl} / \mathrm{PC}$ and $\mathrm{LiCl} / \mathrm{ETA}$, all fall very close to the ideal line of the Walden plot, 
exhibiting a universal behavior. This means that the ionic transport in these samples is closely connected to their fluidity, i.e., Eq. 5 holds.



Figure 3. Relation of molar conductivity $(\Lambda)$ to fluidity $(1 / \eta)$ for various ionic conductors. CKN stands for the ionic glass former $\left[\mathrm{Ca}\left(\mathrm{NO}_{3}\right)_{2}\right]_{0.4}\left[\mathrm{KNO}_{3}\right]_{0.6}$ [75]. $\alpha$ Pic-Ac stands for $\alpha$-picolinium acetate [72]. MOPAN is methoxylpropylammonium nitrate [72]. 2E4MIm is 2-ethyl-4-methylimidazole, a molecular proton conductor. PC and ETA stand for propylene carbonate and ethanolamine, respectively. $\mathrm{LiCl} / \mathrm{H}_{2} \mathrm{O}$ is an aqueous solution. $\mathrm{LiCl} / \mathrm{PC}$ and $\mathrm{LiCl} / \mathrm{ETA}$ are non-aqueous solutions [76]. 1-butyl-3-methylimidazolium hexafluorophosphate $\left([\mathrm{BMIM}]\left[\mathrm{PF}_{6}\right]\right)$ and 1-butyl-3-methyl-imidazole trifluoroacetate ([BMIM][TFA]) are aprotic ionic liquids [77]. The data of $(\mathrm{AgI})_{0.5}\left(\mathrm{AgPO}_{3}\right)_{0.5}$ is from refs. [73] and [74]. The open black star represents the dilute $\mathrm{LiClO}_{4}$ aqueous solution at room temperature [78], and is used as a benchmark. The straight line with slope of 1.0 is the "ideal" Walden line, which divides the Walden plot into superionic (above the ideal line) and subionic (below the ideal line) regimes. This classification does not strongly depend on the choice of the reference. The relation between $\Lambda$ and $1 / \eta$ typically can be characterized by a power law: $\Lambda \eta^{\alpha}=$ Const., which reduces to the classical Walden rule when $\alpha=1$. The slope $\alpha$ provides a measure of the degree of decoupling between ionic transport and fluidity. 
4.2 Relationship between ionic transport and structural relaxation in polymers

As already pointed out earlier, for small molecules and ceramics, their viscosity is related to their structural relaxation time through the Maxwell relation: $\eta=G_{g} \tau_{\mathrm{S}}$. In this case, one can use either macroscopic viscosity $(\eta)$ or structural relaxation time $\left(\tau_{\mathrm{S}}\right)$ to construct the Walden plot. However, for polymer electrolytes, the microscopic segmental friction instead of macroscopic viscosity is the more relevant quantity for ionic transport in polymers, i.e., $\mu_{q} \propto \eta_{\text {micro }}^{-1}[8,13,25,44,79]$. Since according to the classical theory, Eq. 6 should be valid for both small molecule and polymeric electrolytes, we can use this relation as the basis for extending the Walden plot analysis to polymers.

In the modified Walden plot (Fig. 4), the fluidity $(1 / \eta)$ is substituted by the rate of structural relaxation $\left(1 / \tau_{\mathrm{S}}\right)$. This modification makes it possible to directly compare the molar conductivities of the studied polymer electrolytes to those of other well-known ionic conductors, including aprotic ionic liquids (ILs) [BMIM][PF6], [BMIM][TFA],[77] aqueous $\mathrm{LiCl}$ solution (24\%) [80], and the molten salt CKN [75]. Because of the Maxwell relation $\left(\eta=G_{g} \tau_{\mathrm{S}}\right)$, the behavior of these electrolytes in the modified Walden plot (Fig. 4) is very similar to that in the traditional Walden plot (Fig. 3). The ILs and $\mathrm{LiCl} / \mathrm{H}_{2} \mathrm{O}$ fall close to the ideal line of the Walden plot, because of their strong coupling between ionic transport and structural relaxation $[65,81]$. CKN also follows the ideal line at high temperatures (short $\tau_{\mathrm{S}}$ ), but deviates near the glass transition, showing the well-known superionic behavior.

Similar to ILs, the flexible polymers PEO and PPO lie almost perfectly on the ideal line, indicating a strong coupling of ionic transport to structural relaxation and good ion solvation. Although only two samples are shown here, this is in fact a universal behavior for all PEO and PPO based electrolytes, regardless of polymer molecular weight and salt concentration $[25,44,82,83]$. In the case of polyethers, the Walden plot provides a simple estimate for the rate of segmental relaxation required to achieve conductivity $\sim 10^{-3} \mathrm{~S} / \mathrm{cm}$ [82]. Lithium content in PEO even at $50 \mathrm{wt} \%$ of salt LiTFSI is only $\sim 1.2 \mathrm{wt} \%$. Thus the required molar conductivity to reach $\sigma=10^{-3} \mathrm{~S} / \mathrm{cm}$ should be $\sim 0.6 \mathrm{Scm}^{2} / \mathrm{mol}$, even if we 
assume that all salts are completely dissociated. In polymers like PEO and PPO this is possible only when segmental relaxation is faster than $\sim 10^{-8}$ s (Fig. 4), which can be achieved only at temperatures much higher than ambient.

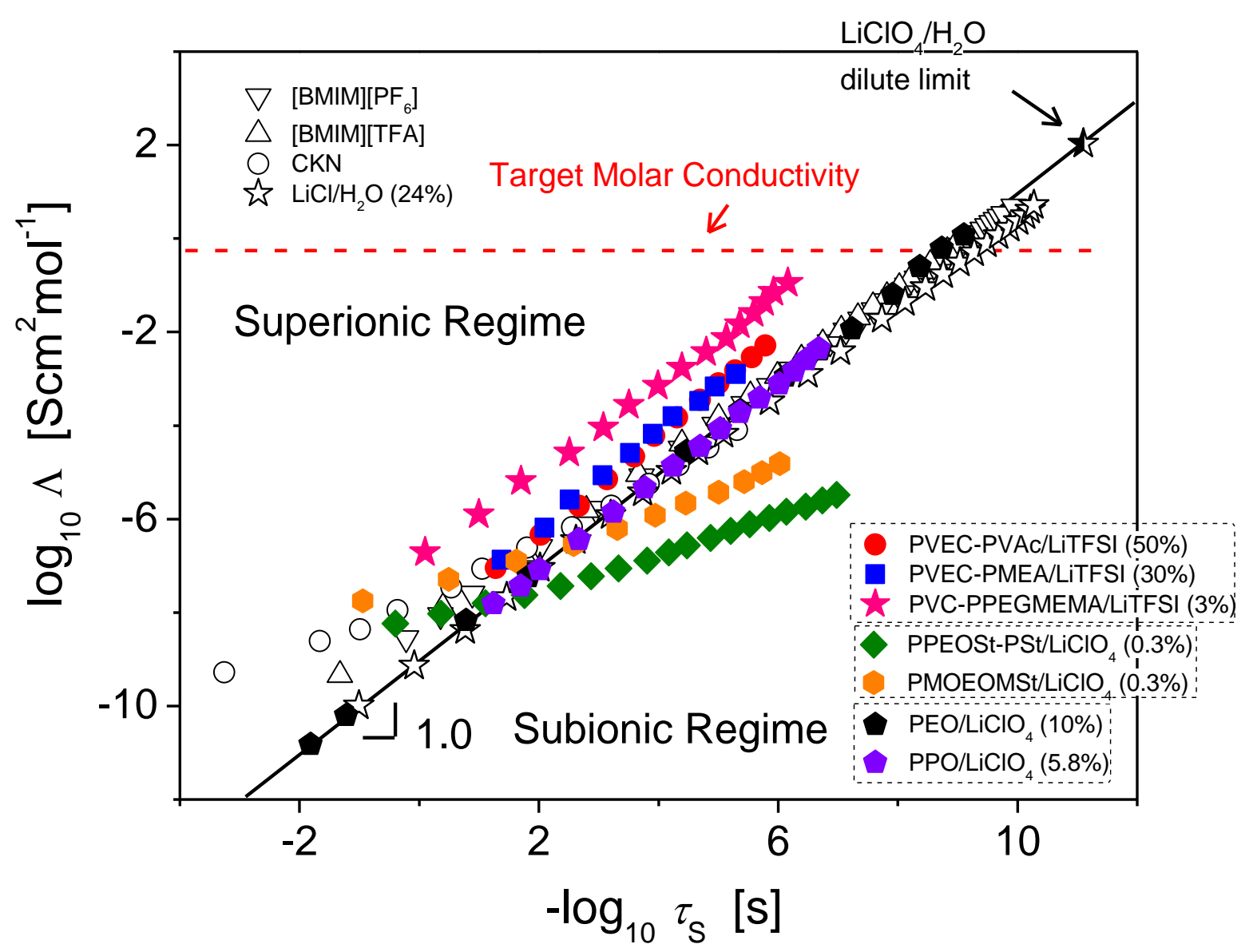

Figure 4. Relationship of apparent molar conductivity $(\Lambda)$ to structural relaxation rate $\left(1 / \tau_{\mathrm{S}}\right)$ for various electrolytes (modified Walden plots). The PEO data are taken from ref. [25]. The horizontal dashed line indicates the target molar conductivity required to achieve $\sigma=10^{-3} \mathrm{~S} / \mathrm{cm}$ in PEO/LiTFSI system. The calculation is based on a polymer electrolyte with $50 \mathrm{wt} \%$ of LiTFSI, assuming the density is $1.0 \mathrm{~g} / \mathrm{cm}^{3}$ and complete salt dissociation.

In contrast to the behavior of PEO and PPO, strong decoupling of ionic conductivity from segmental dynamics is found in the rigid (fragile) polymers PMOEOMSt and PPEOSt-PSt. In these samples, the relation between $\Lambda$ and $\tau_{\mathrm{S}}$ can be described by a fractional Walden's rule: $\Lambda\left(\tau_{\mathrm{S}}\right)^{\alpha}=$ const. where $\alpha<1$. This implies that the ionic conductivity is much less sensitive to the temperature change than the structural relaxation $[14,17]$. As a result, PMOEOMSt and PPEOSt-PSt appear in the 
superionic regime in the vicinity of the glass transition. The most surprising results come from carbonate-based polymers: they stay well above the ideal line, exhibiting superionic behavior over the entire studied temperature range. In particular, PVC-PPEGMEMA/LiTFSI (3\%) has a molar conductivity two orders above the ideal line. This result reveals that the rate of ionic motion in these polymers is much faster than the rate of structural relaxation. The molar conductivity in these polymers is significantly higher than in the traditional polymer electrolyte PEO at the same $\tau_{\mathrm{S}}$ (Fig. 4). While the slope $\alpha$ for styrene-based polymers is significantly smaller than 1.0, $\alpha$ in carbonate-based polymer is close to 1.0. This suggests that the interaction between ions and the polymer matrix may play an important role in determining the coupling between ionic transport and structural relaxation (in terms of temperature dependence). The weak interaction between the ions and the polymer matrix might be the cause for different temperature dependence of conductivity and segmental relaxation in PPEOSt-PSt and

\section{PMOEOMSt.}

\subsection{Consideration of true free ion concentration}

The Walden plot analysis in Fig. 4 is carried out under the assumption of complete salt dissociation. In reality, salts typically do not fully dissociate, due to the mediocre solvating power of polymers, and only a small fraction of ions exists as "free ions". The use of apparent molar conductivity $(\Lambda)$ thus underestimates the true mobility of free ions. In order to estimate the true molar conductivity of free ions $\left(\Lambda_{\text {True }}\right)$, we adopt an empirical method based on the analysis of the electrode polarization (EP) effect [26] in dielectric spectroscopy $[17,84]$. This method is based on the Macdonald-Trukhan model of electrode polarization $[30,31,33,35,85-87]$, but additional corrections are introduced in order to account for the failure of the model at high salt concentration [84].

According to the Macdonald-Trukhan model, the (average) free ion diffusivity $(D)$ can be calculated as:

$$
D=\frac{2 \pi f_{\max } L^{2}}{32(\tan \delta)_{\max }^{3}},
$$


where $f_{\max }$ and $(\tan \delta)_{\max }$ are the frequency and the amplitude of the electrode polarization $\tan \delta$ maximum

(Fig. 5a and b), $L$ is the sample thickness. The free-ion concentration can be obtained from $\sigma$ and $D$ according to the definition of conductivity and the Einstein relation:

$$
n=\frac{\sigma k_{\mathrm{B}} T}{D q^{2}} .
$$
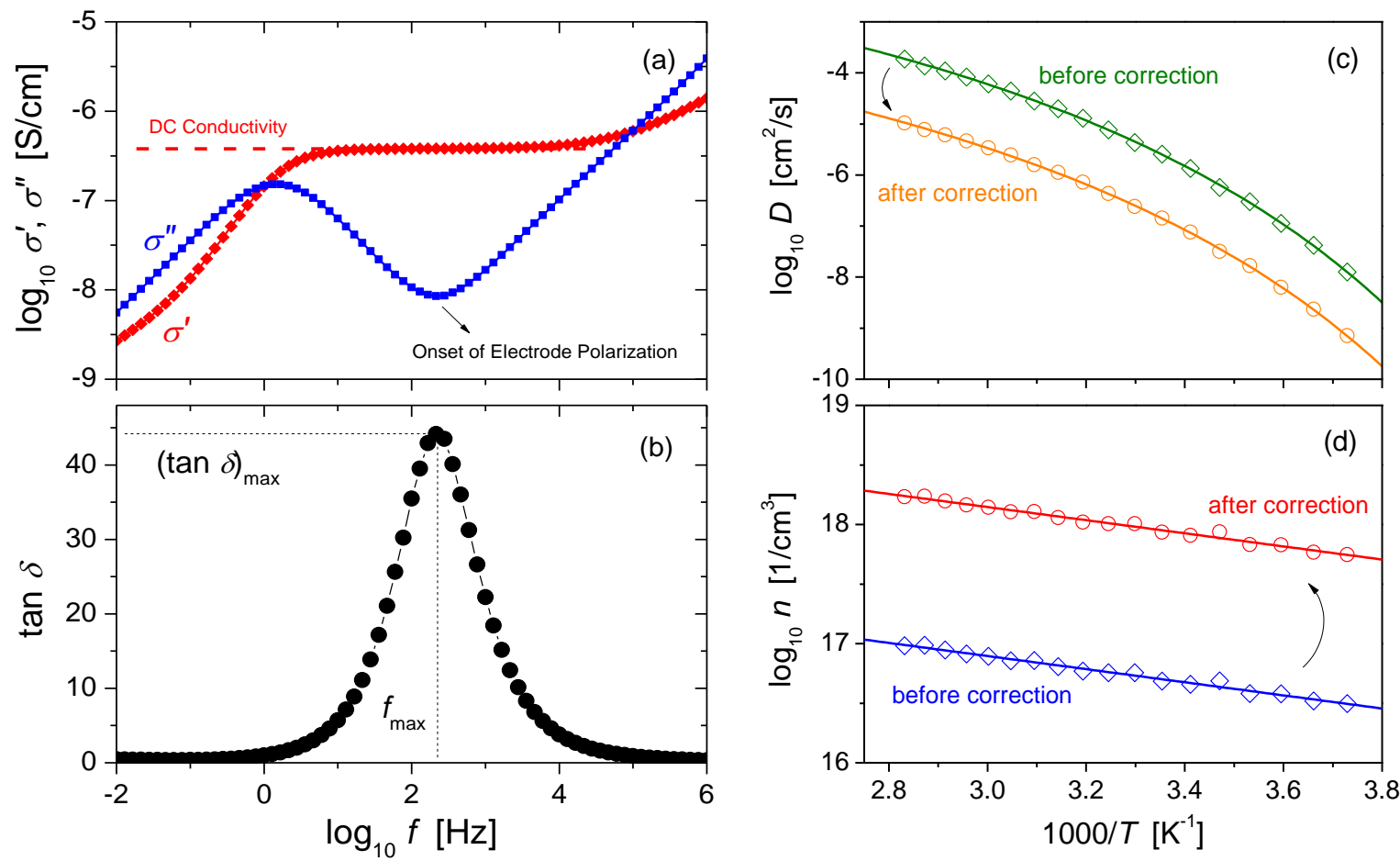

Figure 5. Demonstration of the electrode polarization analysis of PVC-PPEOMEMA/LiTFSI (3 wt $\%)$. (a) and (b) show that the analysis is done at the onset of EP where $\sigma^{\prime \prime}$ displays a minimum and $\tan \delta$ exhibits a maximum. The corresponding $f_{\max }$ and $(\tan \delta)_{\max }$ are used to evaluate the true molar conductivity $\left(\Lambda_{\text {True }}\right)$ according to equations 8-12. (c) and (d) show the temperature dependence of the calculated diffusivity and free-ion number density, respectively. The diamonds represent the free-ion number density and diffusivity calculated using Eq. 8 and 9. The circles are the data after correction using Eq. 11 and 12.

An example of EP analysis is given in Fig. 5. The calculated free-ion number density follows Arrhenius temperature dependence:

$$
n=n_{0} \exp \left(-E_{\mathrm{dis}} / k_{\mathrm{B}} T\right)
$$

Here, $E_{\mathrm{dis}}$ is the dissociation energy and $n_{0}$ is the number density in the high-temperature limit. 
In our previous work [84], we proposed that the free-ion number density and diffusivity should be corrected by using a proportionality constant. This correction is related to the fact that the effects of surface roughness and chemical composition of electrodes are not considered in the current EP model. Assuming complete dissociation in the infinite high temperature limit, the true free-ion number density should be described by the following Arrhenius equation:

$$
\tilde{n}=\frac{n_{\mathrm{tot}}}{n_{0}} n=\frac{n_{\mathrm{tot}}}{n_{0}}\left[n_{0} \exp \left(-E_{\mathrm{dis}} / k_{\mathrm{B}} T\right)\right]=n_{\mathrm{tot}} \exp \left(-E_{\mathrm{dis}} / k_{\mathrm{B}} T\right)
$$

where $\tilde{\boldsymbol{n}}$ is the free-ion concentration after correction, $n_{\text {tot }}$ is the total ion concentration at full dissociation, and $E_{\mathrm{dis}}$ is the dissociation energy determined by Eq. 10. Similarly, the ion diffusivity should be corrected by a factor of $n_{0} / n_{\text {tot }}$ :

$$
\tilde{D}=D \frac{n_{0}}{n_{\text {tot }}}
$$

where $\tilde{D}$ is the diffusivity after correction and $D$ is the original diffusivity from EP analysis. Details of the EP analysis has been presented in ref. [84], where it has been also shown that this method could yield free-ion number density and diffusivity that are in reasonable agreement with PFG-NMR measurements [84]. 


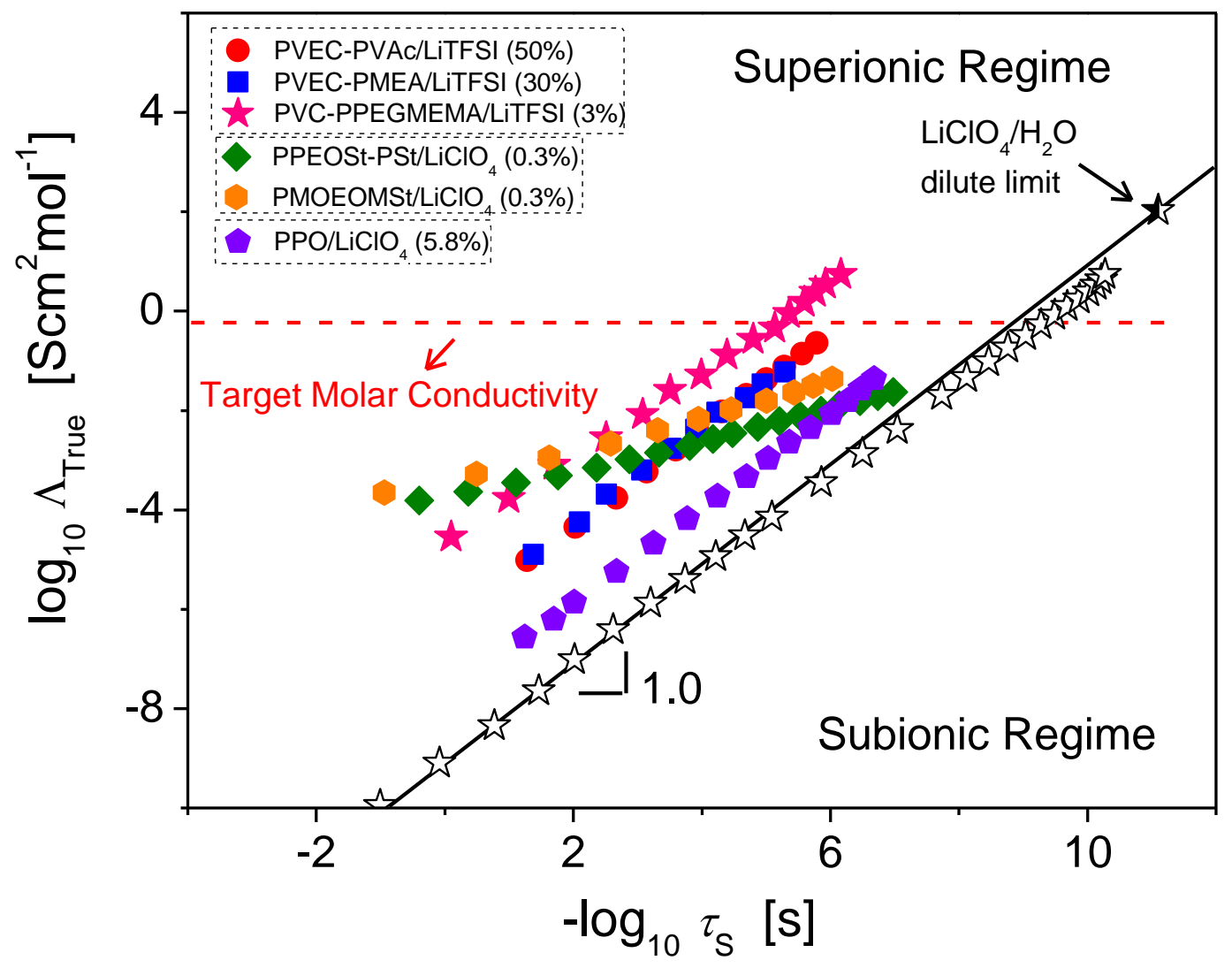

Figure 6. Relationship of true molar conductivity $\left(\Lambda_{\text {True }}\right)$ to structural relaxation rate $\left(1 / \tau_{\mathrm{S}}\right)$ for various electrolytes. The open stars: $\mathrm{LiCl} / \mathrm{H}_{2} \mathrm{O}(24 \%)$.

The true molar conductivities estimated using this approach for all the polymer electrolytes appear in the superionic regime (Fig. 6). Even PPO is slightly above the ideal line. It should be stressed that the analysis of the apparent molar conductivity in Fig. 4 is model independent, whereas the analysis in Fig. 6 clearly depends on the validity of the EP model. Thus the general trend depicted in Fig. 6 should be regarded only as qualitative, i.e., the true molar conductivities of many polymer electrolytes are indeed in the superionic regime. These results demonstrate a strong decoupling of the rate of charge transport from the rate of structural relaxation in polymers. The largest decoupling is found in PMOEOMSt/LiClO 4 near $T_{\mathrm{g}}$, where the true molar conductivity of the sample is more than six orders of magnitude higher than that in the "ideal" $\mathrm{LiClO}_{4}$ dilute solution at the same rate of structural relaxation. 
4.4 Comparison with small-molecule electrolytes

Previous studies have shown that most of the liquid electrolytes, including aqueous and nonaqueous solutions, protic and aprotic ionic liquids, fall either very close to or below the "ideal" Walden line (Fig. 3) [69, 71, 72]. This means that at a given structural relaxation rate, the molar ionic conductivity in aqueous solutions can be regarded as an upper limit for liquid electrolytes. Additionally, liquid electrolytes typically exhibit a slope of $\sim 1.0$ on the Walden plot, because of strongly coupled ionic conductivity. The Walden plot analyses in Figs. 4 and 6 reveal that the intrinsic relationship between ionic transport and structural relaxation in polymer electrolytes can be fundamentally different from that in small-molecule liquid electrolytes. First, the ionic transport in polymers can be much less sensitive to the change of temperature [17]. This is demonstrated by the fractional Stokes-Einstein behavior of the styrene-based polymers. Second, at a given structural relaxation rate, the ionic transport in polymers can be much faster than in small-molecule liquid electrolytes, making polymers appear in the superionic regime of the modified Walden plot. These findings have not been predicted by any classical theory and have important implications for the design of solid polymer electrolytes.

\section{Small-Molecule Electrolytes}

$\tau_{1} \approx \tau_{2}$



\section{Polymer Electrolytes}




Figure 7. Illustration of the qualitative difference between the ion transport mechanisms in small molecules and polymers. In small molecules, the characteristic time scales for ionic transport $\left(\tau_{1}\right)$ and structural relaxation $\left(\tau_{2}\right)$ are comparable. In contrast, fast ion transport can occur in polymer electrolytes.

The Walden plot analysis (Figs. 4 and 6) also reveals that polymers with relatively rigid backbones provide stronger decoupling of ionic conductivity and higher true molar conductivity than flexible polymers such as PEO. Flexible polymers are able to form tightly packed structures [88] and in this case ionic diffusion is possible only when segments are moving. In addition, lithium ions are coordinated with the oxygen atoms in the backbone of PEO and PPO. All these factors lead to strong coupling of ionic conductivity to segmental dynamics. Reaching the desired level of ionic conductivity in these types of polymers requires very fast segmental dynamics (Fig. 4). In contrast, relatively rigid polymers have significant frustration in chain packing [88, 89]. This leaves enough space ("free volume") for diffusion of small ions even when segmental dynamics are very slow. As a result, the rate of ionic diffusion is significantly faster than the rate of segmental relaxation (Fig. 4). Moreover, in some polymers the ionic motion is much less sensitive to temperature than the segmental dynamics. The polymers with relatively rigid backbones therefore exhibit true superionic behavior.

Although the $\Lambda_{\text {True }}$ of PPEOSt-PSt and PMOEOMSt shows very desirable "superionic" feature, the actual ionic conductivities in these polymers are still relatively low, due to their low free ion concentrations and relatively high $T_{\mathrm{g}} \mathrm{s}$. By improving solvating properties of these polymers it might be possible to achieve the desired level of ionic conductivity at segmental relaxation time $\tau_{\mathrm{S}} \sim 10^{-4} \mathrm{~s}$ (Fig. 6) or even slower. In this case, properly balancing decoupling with ion solvation would be critical for the future success.

\subsection{Comparison with benchmarks in the literature}

Fig. 8 shows the temperature dependence of the ionic conductivity of three representative polymer electrolytes in our study, together with those of other representative electrolytes used in lithium batteries.[90, 91] Relatively high ionic conductivity has been achieved in the carbonate-based polymer 
electrolytes, i.e., PVEC-PVAc/LiTFSI $\quad(50 \quad$ wt $\%)$, PVEC-PMEA/LiTFSI $\quad(30 \quad$ wt $\%)$, PVCPPEGMEMA/LiTFSI (50 wt\%)]. At high temperatures, the ionic conductivity of PVEC-PVAc/LiTFSI (50 wt\%) is similar to that of PEO/LiTFSI (45 wt\%) [92], which is one of the best traditional dry polymer electrolytes. At low temperatures, PVEC-PVAc/LiTFSI (50 wt $\%$ ) is even slightly better than PEO/LiTFSI (45 wt $\%$ ), partially due to the decoupling. At $60^{\circ} \mathrm{C}$, the conductivity of PVECPVAc/LiTFSI (50 wt\%) is approximately 20 times higher than that of P(STFSILi)- $b$-PEO- $b$-P(STFSILi) [91], which represents the state of the art for single-ion polymeric lithium conductors. Nevertheless, the ionic conductivity of PVEC-PVAc/LiTFSI (50 wt\%) reaches the level required for many applications $\left(10^{-3} \mathrm{~S} / \mathrm{cm}\right)[11]$ only at high temperatures. Although the Walden plot analysis (Figs. 4 and 6) reveals that PVC-PPEGMEMA exhibits the highest degree of decoupling in terms of the relation between $\Lambda$ $\left(\Lambda_{\text {True }}\right)$ and $\tau_{\mathrm{S}}$, the electrolyte based on PVEC-PVAc actually gives the highest level of conductivity (inset of Fig. 8). This is due to the fact that the $T_{\mathrm{g}}$ of PVEC-PVAc/LiTFSI (50 wt $\%$ ) is much lower than that of PVC-PPEGMEMA/LiTFSI $(50 \mathrm{wt} \%)\left(T_{\mathrm{g}}=216 \mathrm{~K}\right.$ for the former, and $243 \mathrm{~K}$ for the later). Achieving high ionic conductivity at a given temperature requires both a high degree of decoupling and a relatively low glass transition temperature (short $\tau_{\mathrm{S}}$ ). It should also be noted that carbonate-based polymers are generally not stable under high voltage. Although as a model system, the carbonate-based polymers in this study have provided invaluable insights, more stable chemical structures such as sulfone- and sulfolane might be considered in the future design of superionic polymers [93-95]. 


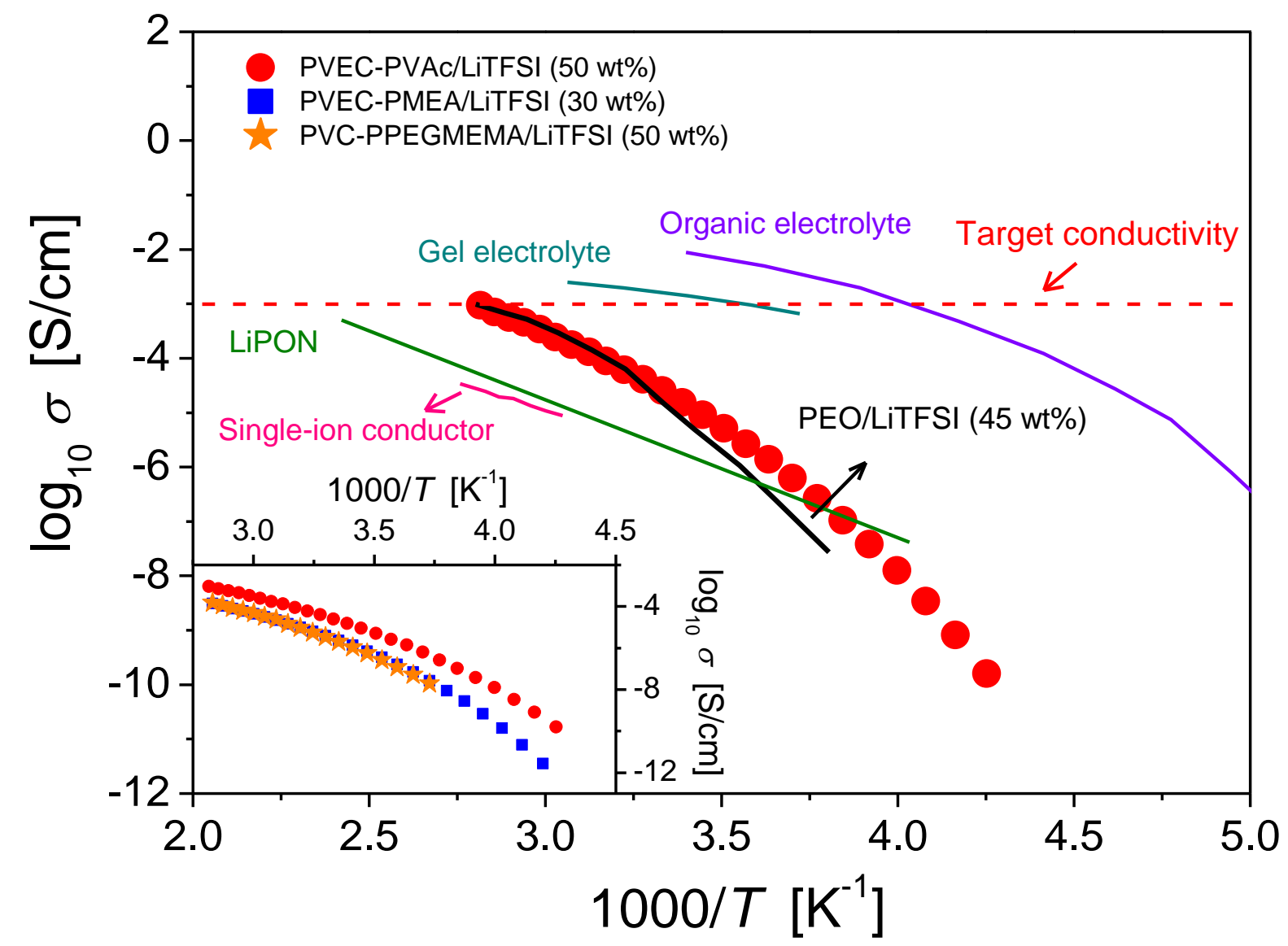

Figure 8. Temperature dependence of ionic conductivity of PVEC-PVAc/LiTFSI (50 wt $\%$ ), together with those of other representative lithium conductors [90]. LiPON stands for the lithium phosphorous oxynitride electrolyte. The gel electrolyte is $1 \mathrm{M} \mathrm{LiPF} / \mathrm{EC}-\mathrm{PC}(50: 50 \mathrm{vol} \%)$ in $10 \mathrm{wt} \%$ of polyvinylidene difluoride-hexafluoropropylene [96]. The organic electrolyte is $1 \mathrm{M} \mathrm{LiPF}_{6} / \mathrm{EC}-\mathrm{PC}$ (50:50 vol\%) [97]. The single-ion conductor is P(STFSILi)- $b$-PEO- $b$-P(STFSILi) [91], which represents the state of the art for this type of material. The PVEC-PVAc/LiTFSI (50 wt\%) sample out-performs the conventional PEO/LiTFSI (45 wt\%) electrolyte [92] in the studied temperature range. The dashed line presents the target value of conductivity $\sigma=10^{-3} \mathrm{~S} / \mathrm{cm}$ that is important for many applications [11]. The inset shows the ionic conductivity of two other promising polymer electrolytes, PVEC-PMEA/LiTFSI (30 wt \%) and PVC-PPEGMEMA/LiTFSI (50 wt\%), along with the data of PVEC-PVAc/LiTFSI (50 $\mathrm{wt} \%)$.

\section{Conclusions}

In conclusion, the analysis of the relation between ionic transport and structural relaxation has revealed a fundamental difference between the ion transport mechanisms in polymers and small- 
molecule liquid electrolytes. Motion of ions is usually coupled to structural relaxation in small-molecule electrolytes and high ionic conductivity is possible due to very short structural relaxation time. In contrast, the ionic transport in polymer electrolytes can be strongly decoupled from structural relaxation, especially in polymers with relatively rigid structures. This result clearly demonstrates that decoupling of ionic conductivity from the segmental dynamics should be the key target property for polymer electrolytes. Ions may utilize the loose local packing structure of long chains, which is not available in small molecules, and diffuse through the polymer matrix even when segmental dynamics are slow or frozen. This behavior is analogous to superionic conductors such as AgI, where the smaller silver ions can "slip" through the quasi-lattice of the larger iodide ions. Combined with strong ion solvating properties, the decoupling concept may lead to the design of a new class of superionic polymer electrolytes with desired levels of ionic conductivity at ambient temperature.

\section{Acknowledgements}

The authors thank Dr. M. Nakanishi for providing the data of electrical conductivity of the lithium chloride solution. T.S., J.M. and A.P.S. acknowledge the financial support from the Division of Materials Science and Engineering, U.S. Department of Energy, Office of Basic Energy Sciences. The polymer synthesis was partly conducted at the Center for Nanophase Materials Sciences, which is sponsored at Oak Ridge National Laboratory by the Scientific User Facilities Division, Office of Basic Energy Sciences, U.S. Department of Energy. F.F. thanks the NSF Polymer Program (DMR-1104824) for funding. 


\section{References}

1. Armand M. Solid State Ionics 1983;9-10:745-754.

2. Armand M, Chabagno JM, Duclot M. Polyethers as Solid Electrolytes. In: Vashitshta P, Mundy JN, and Shenoy GK, editors. Fast Ion Transport in Solids: Electrodes and Electrolytes. Amsterdam: North Holland Publishers, 1979.

3. Di Noto V, Lavina S, Giffin GA, Negro E, Scrosati B. Electrochim Acta 2011;57:4-13.

4. Hallinan DT, Balsara NP. Ann Rev Mater Res 2013;43:503-525.

5. Wright PV. Br Polymer J 1975;7:319-327.

6. Gadjourova Z, Andreev YG, Tunstall DP, Bruce PG. Nature 2001;412:520-523.

7. Agrawal RC, Pandey GP. J Phys D: Appl Phys 2008;41:223001.

8. $\quad$ Ratner MA, Johansson P, Shriver DF. MRS Bull 2000;25:31-37.

9. Scrosati B, Vincent CA. MRS Bull 2000;25:28-30.

10. Tarascon J-M, Armand M. Nature 2001;414:359-367.

11. Wright PV. MRS Bull 2002;27:597-602.

12. Wolynes PG. Ann Rev Phys Chem 1980;31:345-376.

13. Ratner MA, Shriver DF. Chem Rev 1988;88:109-124.

14. Agapov AL, Sokolov AP. Macromolecules 2011;44:4410-4414.

15. Imrie CT, Ingram MD. Electrochim Acta 2001;46:1413-1417.

16. Sasabe H, Saito S. Polymer J 1972;3:624-630.

17. Wang Y, Agapov AL, Fan F, Hong K, Yu X, Mays J, Sokolov AP. Phys Rev Lett 2012;108:088303.

18. Wei X, Shriver DF. Chem Mater 1998;10:2307-2308.

19. Boyce JB, Huberman BA. Phys Rep 1979;4:189-265.

20. Ingram MD. Curr Opin Solid State Mater Sci 1997;2:399-404.

21. Hull S. Rep Prog Phys 2004;67:1233-1314. 
22. Minami T. J Non-Cryst Solids 1987;95-96:107-118.

23. Hua F, Yuan W, Britt PF, Mays JW, Hong K. Soft Matter 2013;9:8897-8903.

24. Wang Y, Fan F, Agapov AL, Yu X, Hong K, Mays J, Sokolov AP. Solid State Ionics 2014;262:782-784.

25. Yoshida K, Manabe H, Takahashi Y, Furukawa T. Electrochim Acta 2011;57:139-146.

26. Serghei A, Sangoro JR, Kremer F. Broadband Dielectric Spectroscopy on Electrode Polarization and Its Scaling. In: Ohshima H, editor. Electrical Phenomena at Interfaces and Biointerfaces: Fundamentals and Applications in Nano-, Bio-, and Environmental Sciences. Hoboken, New Jersey: John Wiley \& Sons, Inc., 2012.

27. Alexe-Ionescu AL, Barbero G, Lelidis I. Phys Rev E 2009;80:061203.

28. Bordi F, Cametti C, Gili T. Bioelectrochem 2001;54:53-61.

29. Feldman Y, Polygalov E, Ermolina I, Polevaya Y, Tsentsiper B. Meas Sci Technol 2001;12:1355-1364.

30. Klein RJ, Zhang SH, Dou S, Jones BH, Colby RH, Runt J. J Chem Phys 2006;124:144903.

31. Macdonald JR. Phys Rev 1953;92:4-17.

32. Schwan HP. Ann N Y Acad Sci 1968;148:191-209.

33. Sørensen TS, Compañ V. J Chem Soc Faraday Trans 1995;91:4235-4250.

34. Stoneman MR, Kosempa M, Gregory WD, Gregory CW, Marx JJ, Mikkelson W, Tjoe J, Raicu V. Phys Med Biol 2007;2007:6589-6604.

35. Trukhan EM. Sov Phys Solid State (Engl Transl) 1963;4:2560.

36. Uemura S. J Polym Sci Polym Phys Ed 1972;10:2155-2166.

37. Serghei A, Tress M, Sangoro JR, Kremer F. Phys Rev B 2009;80:184301.

38. Wübbenhorst M, van Turnhout J. J Non-Cryst Solids 2002;305:40-49.

39. Richert R, Agapov A, Sokolov AP. J Chem Phys 2011;134:104508.

40. Kremer F, Schohals A. Broadband Dielectric Spectroscopy. Berlin: Springer-Verlag, 2002.

41. Fulcher GS. J Amer Ceram Soc 1925;8:339-355. 
42. Tammann G, Hesse W. Z Anorg Allg Chem 1926;156:245-257.

43. Vogel H. J Phys Z 1921;22:645-646.

44. Fan F, Wang Y, Sokolov AP. Macromolecules 2013;46:9380-9389.

45. Hansen JP, McDonald IR. Theory of simple liquids. London: Academic Press, 2006.

46. Bagchi B. J Chem Phys 1998;109:3989-3993.

47. Bagchi B, Biswas R. Acc Chem Res 1998;31:181-187.

48. Biswas R, Roy S, Bagchi B. Phys Rev Lett 1995;75:1098-1101.

49. $\quad$ Biswas R, Roy S, Bagchi B. Phys Rev Lett 1996;76:556-556.

50. Chandra A, Bagchi B. J Chem Phys 1999;110:10024-10034.

51. Colonomos P, Wolynes PG. J Chem Phys 1979;71:2644-2651.

52. Hubbard J. J Chem Phys 1978;68:1649-1663.

53. Hubbard J, Onsager L. J Chem Phys 1977;67:4850-4857.

54. Wolynes PG. J Chem Phys 1978;68:473-483.

55. Zwanzig R. J Chem Phys 1963;38:1603-1605.

56. Zwanzig R. J Chem Phys 1970;52:3625-3628.

57. Namikawa H. Journal of Non-Crystalline Solids 1975;18:173-195.

58. Barton JL. Verres Refract 1966;20:328.

59. Nakajima T. Conference on Electric Insulation and Dielectric Phenomena, Annual Report. Washington DC: National Academy of Sciences, 1971. pp. 168.

60. Hodge IM, Ingram MD, West AR. J Electroanal Chem 1975;58:429-432.

61. Hodge IM, Ingram MD, West AR. J Electroanal Chem 1976;74:125-143.

62. Macedo PB, Moynihan CT, Bose R. Phys Chem Glasses 1972;13:171-179.

63. Macdonald JR, Johnson WB. Fundamentals of Impedance Spectroscopy. In: Barsoukov E and Macdonald JR, editors. Impedance Spectroscopy: Theory, Experiment, and Applications. Hoboken, New Jersey: John Wiley \& Sons, Inc., 2005.

64. Paluch M. J Phys: Condens Matter 2000;12:9511-9524. 
65. Sangoro JR, Serghei A, Naumov S, Galvosas P, Kärger J, Wespe C, Bordusa F, Kremer F. Phys Rev E 2008;77:051202.

66. Choi UH, Mittal A, Price TL, Gibson HW, Runt J, Colby RH. Macromolecules 2013;46:11751186.

67. Wojnarowska Z, Wang Y, Paluch KJ, Sokolov AP, Paluch M. Physical Chemistry Chemical Physics 2014;16:9123-9127.

68. Walden P. Z Physik Chem 1906;55:207-249.

69. $\quad \mathrm{Xu} \mathrm{W}$, Angell CA. Science 2003;302:422-425.

70. Vanýsek P. Ionic conductivity and diffusion at infinite dilution. In: Haynes WM, editor. CRC Handbook of Chemistry and Physics. Boca Raton: CRC Press, 2012.

71. Angell CA, Ansari Y, Zhao Z. Faraday Discuss 2012;154:9-27.

72. Belieres J-P, Angell CA. J Phys Chem B 2007;111:4926-4937.

73. Malugani JP, Wasniewski A, Doreau M, Robert G. Mat Res Bull 1978;13:427-433.

74. Takahashi H, Hiki Y, Kobayashi H. J Appl Phys 1998;84:213-218.

75. Howell FS, Bose RA, Macedo PB, Moynihan CT. J Phys Chem 1974;78:639-648.

76. Krumgalz BS. J Chem Soc Faraday Trans I 1983;79:571-587.

77. Griffin PJ, Agapov AL, Sokolov AP. Phys Rev E 2012;86:021508.

78. Robinson RA, Stokes RH. Electrolyte Solutions, Second ed. London: Butterworths Scientific Publications, 1959.

79. Mendolia MS, Farrington GC. Chem Mater 1993;5:174-181.

80. Nakanishi M, Griffin PJ, Mamontov E, Sokolov AP. J Chem Phys 2012;136:124512.

81. Sangoro JR, Iacob C, Serghei A, Friedrich C, Kremer F. Phys Chem Chem Phys 2009;11:913916.

82. Wang Y, Fan F, Agapov AL, Yu X, Hong K, Mays J, Sokolov AP. Solid State Ionics 2014.

83. Furukawa T, Mukasa Y, Suzuki T, Kano K. J Polym Sci Part B: Polym Phys 2002;40:613-622. 
84. Wang Y, Sun C-N, Fan F, Sangoro JR, Berman MB, Greenbaum SG, Zawodzinski TA, Sokolov AP. Phys Rev E 2013;87:042308.

85. Macdonald JR. J Phys: Condens Matter 2010;22:495101.

86. Macdonald JR, Evangelista LR, Lenzi EK, Barbero G. J Phys Chem C 2011;115:7468-7655.

87. Fragiadakis D, Dou S, Colby RH, Runt J. Macromolecules 2008;41:5723-5728.

88. Kunal K, Robertson CG, Pawlus S, Hahn SF, Sokolov AP. Macromolecules 2008;41:7232-7238.

89. Dudowicz J, Freed KF, Douglas JF. J Phys Chem B 2005;109:21285-21292.

90. Kamaya N, Homma K, Yamakawa Y, Hirayama M, Kanno R, Yonemura M, Kamiyama T, Kato Y, Hama S, Kawamoto K, Mitsui A. Nature Mater 2011;10:682-686.

91. Bouchet R, Maria S, Meziane R, Aboulaich A, Lienafa L, Bonnet J-P, Phan TNT, Bertin D, Gigmes D, Devaux D, Denoyel R, Armand M. Nature Mater 2013;12:452-457.

92. Edman L, Ferry A, Doeff MM. J Mater Res 2000;15:1950-1954.

93. Lee S-Y, Ueno K, Angell CA. J Phys Chem C 2012;116:23915-23920.

94. Abouimrane A, Belharouak I, Amine K. Electrochemistry Communications 2009;11:1073-1076.

95. Xu K. Chem Rev 2004;104:4303-4418.

96. Song JY, Wang YY, Wan CC. J Electrochem Soc 2000;147:3219-3225.

97. Stallworth PE, Fontanella JJ, Wintersgill MC, Scheidler CD, Immel JJ, Greenbaum SG, Gozdz AS. J Power Sources 1999;81-82:739-747. 


\section{Small-Molecule Electrolytes}

$\tau_{1} \approx \tau_{2}$ ionic transport $\left(\tau_{1}\right)$

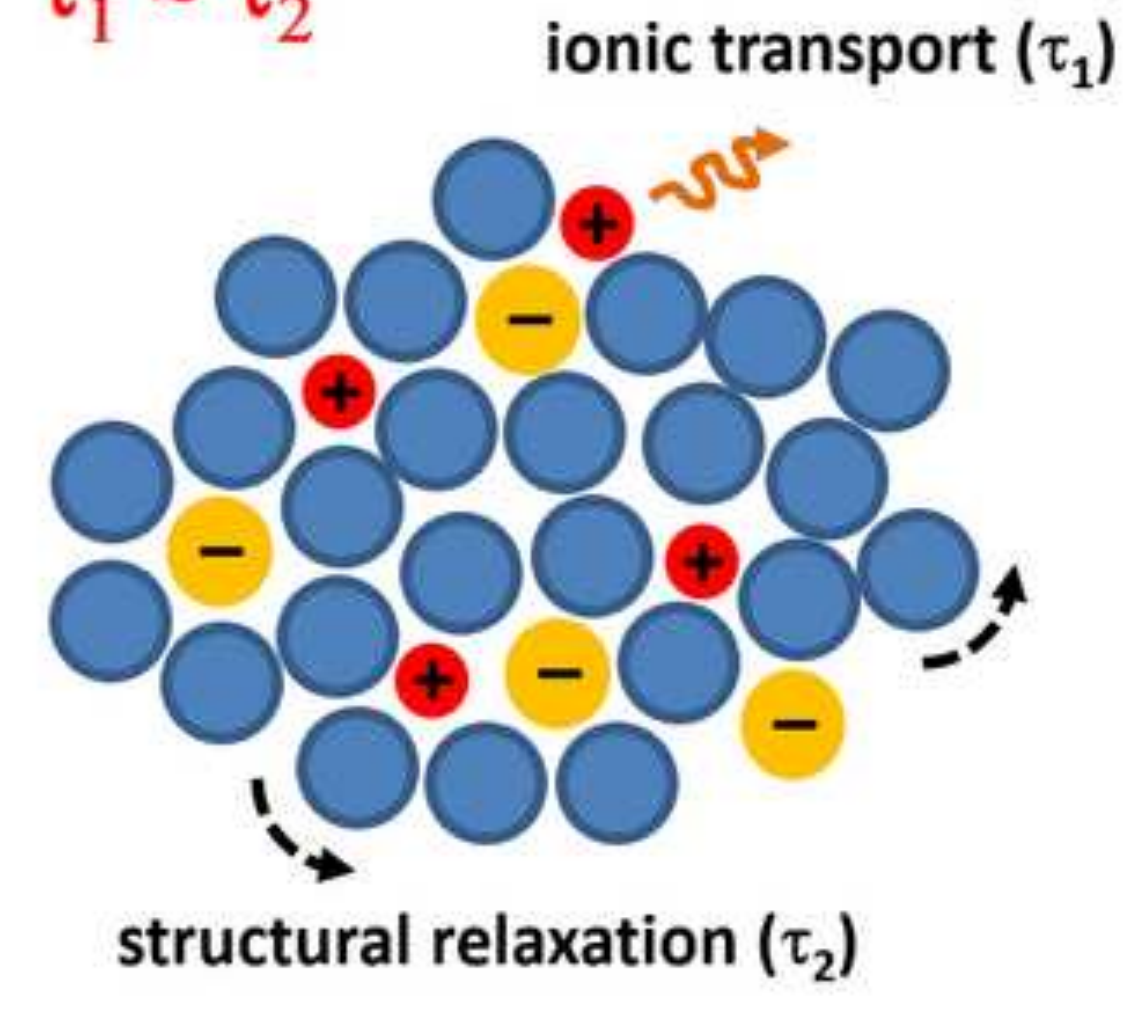

structural relaxation $\left(\tau_{2}\right)$

\section{Polymer Electrolytes}

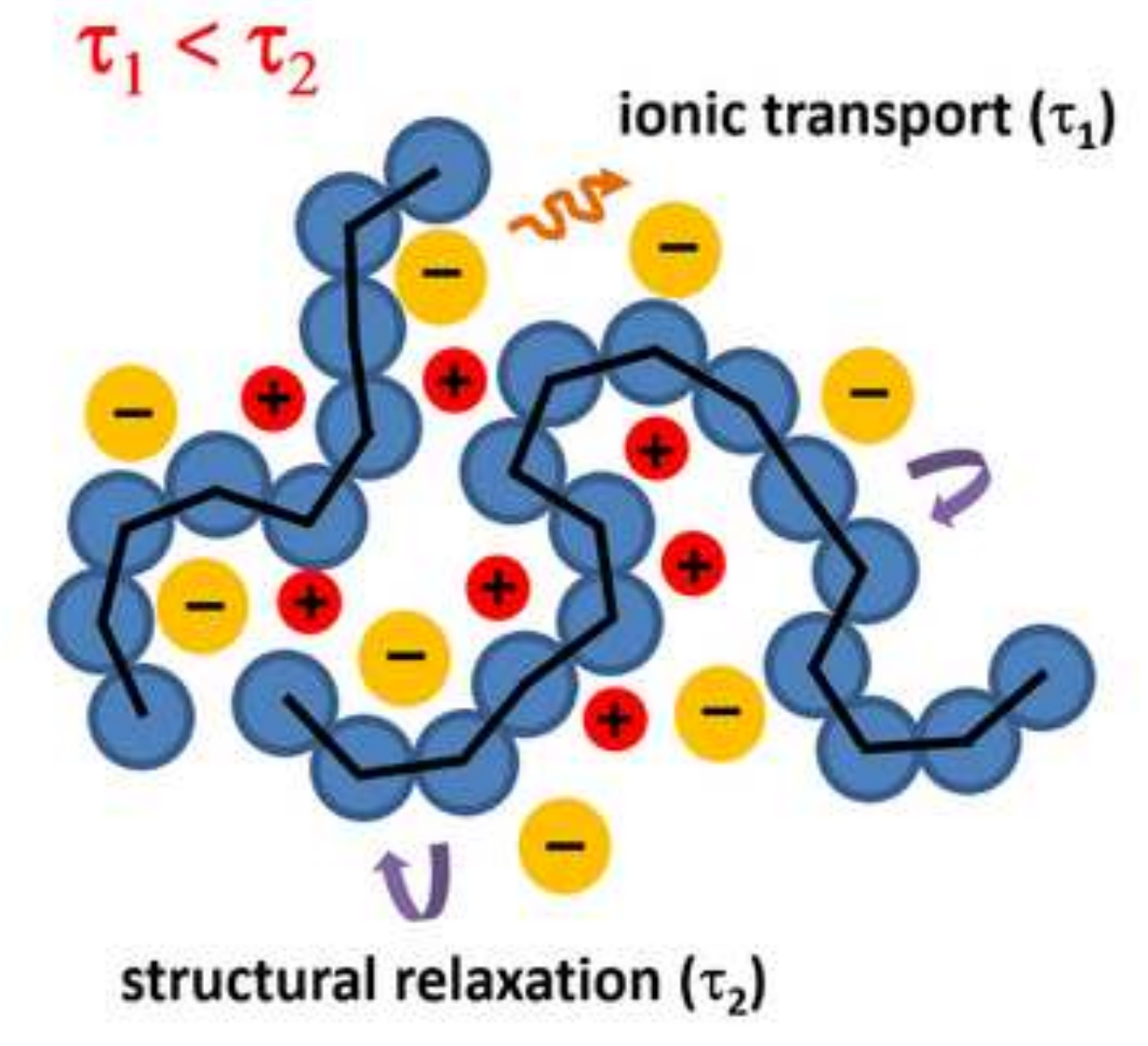

